\title{
Numerical simulation of slope stability of the abandoned dreg site
}

\author{
Xiao Wang ${ }^{1 *}$, Zhigang Deng ${ }^{2}$, Dong $\mathrm{Ni}^{1}$, Dong Zhang ${ }^{1}$ and Jing Zhao ${ }^{1}$ \\ ${ }^{1}$ Research Institute of Highway Ministry of Transport, Beijing, 100088, China \\ ${ }^{2}$ Guangdong Huiqing Expressway Co., Ltd., Guangzhou, Guangdong Province, 510900, China
}

\begin{abstract}
A mathematical model of No. 1 abandoned dreg site of the newly-built highway from Xiangle village, Pingyao County to Hougou village, Qinyuan County was developed using GeoStudio software. The stability of the abandoned dreg site was simulated and analyzed under rainstorm. As a result, the influence of rainfall infiltration on slope seepage field is not limited to the rainfall process. The slope stability coefficient decreases significantly during the rainfall and the decreases slightly after the rainfall stopped due to continuous rainwater seepage. The minimum safety coefficient is 2.292 at $24 \mathrm{~h}$, greater than the allowable value, which demonstrates that the slope is stable.
\end{abstract}

\section{Introduction}

During highway construction, plenty of abandoned dregs would be produced in subgrade and tunnel engineering. The large-scale abandoned dreg site thus was formed with the continuous accumulation of dregs. The irregular loose slope formed by natural stacking of abandoned dregs can easily cause serious soil and water loss under adverse conditions such as rainfall or earthquake, and even cause geological disasters such as landslide and debris flow, seriously threatening the surrounding environment and the safety of residents and their property. This problem has attracted the attention of scholars at home and abroad, and a series of studies have been performed on the stability of abandoned dreg site ${ }^{[1-}$ ${ }^{2]}$, and the obtained research results have also been widely applied in practice. At present, two common methods are often applied for the stability analysis: one finite element strength reduction method(SRM) ${ }^{[3-4]}$, another limit equilibrium method(LEM $)^{[5-7]}$.

The seepage field of No. 1 abandoned dreg site of the newly-built highway from Xiangle village, Pingyao County to Hougou village, Qinyuan County was studied using unsaturated seepage theory. Based on the seepage calculation results, the limit equilibrium method was used to simulate the slope stability, which provides theoretical basis for the safety assessment of the abandoned dreg site.

\section{The project}

\subsection{Geographic and geomorphic conditions}

The project began in Jinzhong basin, west of Pingyao county, ends in the hinterland of TaiYue mountains, at the border of Pingyao county and Qinyuan county. The route is of dramatic topographic fluctuation along the start-end with significant differences in morphology. The terrain is generally low in the northwest and high in the south and east, with obvious ladder-shaped characteristics. The lowest altitude is $737 \mathrm{~m}$, located at the starting point of the route and the highest point is near Shennan Tunnel at the watershed between Pingyao and Qinyuan, with an altitude of $1607.9 \mathrm{~m}$. The maximum relative altitude difference is up to $870.9 \mathrm{~m}$.

\subsection{Climate}

The project is located in the warm temperate continental monsoon climate zone, with an average annual temperature of $10.4^{\circ} \mathrm{C}$, an extreme maximum temperature of $39.6^{\circ} \mathrm{C}$, an extreme minimum temperature of $-24.1{ }^{\circ} \mathrm{C}$, and a frost-free period of 160 days. The average annual rainfall is $415.5 \mathrm{~mm}$, and most of the precipitation is concentrated in July, August and September, accounting for more than $75 \%$ of the total annual precipitation. The average annual evaporation capacity is $1932.9 \mathrm{~mm}$. The depth of frozen soil is $55 \sim 80 \mathrm{~cm}$.

\section{The slope model}

\subsection{Calculation section}

The abandoned dreg site is located in Pingyao County, Shanxi Province, with an area of about $4.11 \mathrm{hm} 2$. The designed dreg height id $1030 \sim 1050 \mathrm{~m}$ and the designed drag capacity is about $420000 \mathrm{~m} 3$. Figure 1 depicts the abandoned dreg site plan and section, in the same

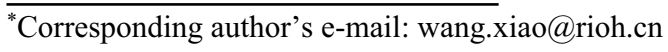


direction with the slope and perpendicular to the topographic contours.

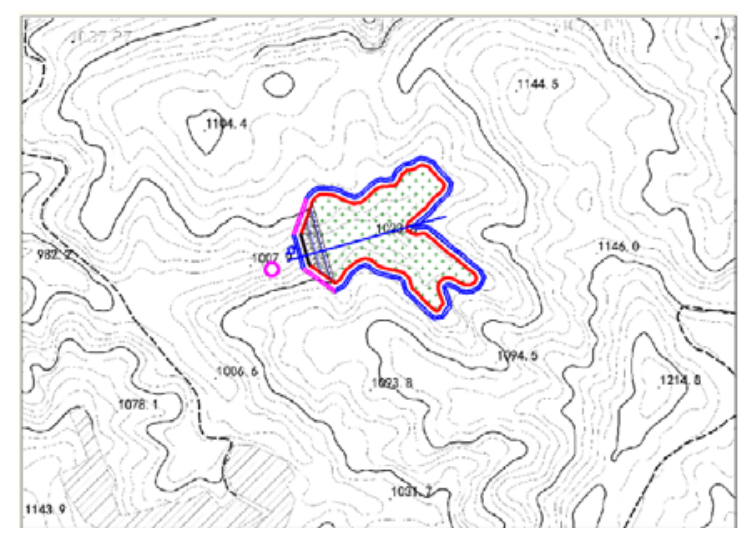

Figure 1. The abandoned dreg site plan and section

\subsection{Boundary conditions and calculation parameters}

The boundary conditions of the model are:

(1) The surface of the slope is the infiltration boundary, which is set as the flow boundary. The infiltration rate varies with the infiltration capacity of rock and soil, when the rainfall intensity is less than the surface infiltration capacity of rock and soil mass, the

Table 1. Physical and mechanical parameters of rock and soil mass.

\begin{tabular}{ccccc}
\hline $\begin{array}{c}\text { Rock and soil } \\
\text { mass type }\end{array}$ & $\begin{array}{c}\text { Density } \\
\rho\left(\mathrm{kN} \cdot \mathrm{m}^{-3}\right)\end{array}$ & $\begin{array}{c}\text { Internal } \\
\text { friction } \\
\text { angle } \\
\varphi(\mathrm{a})\end{array}$ & $\begin{array}{c}\text { Cohesion } \\
\mathcal{C}(\mathrm{kPa})\end{array}$ & $\begin{array}{c}\text { Coefficient of } \\
\text { permeability } \\
\left(\mathrm{ms}^{-1}\right)\end{array}$ \\
\hline $\begin{array}{c}\text { Abandoned } \\
\text { dreg }\end{array}$ & 1.51 & 45.3 & 0 & $6.5 \times 10^{-5}$ \\
\hline
\end{tabular}

\section{The simulation results}

\subsection{Seepage analysis}

Figure 2 depicts the seepage fields of the slope at different times. As can be seen from the figure, the rain infiltration rate is equal to the rainfall intensity. At this time, flow boundary condition is set:

$$
\left.k_{n} \frac{\partial \theta}{\partial n}\right|_{\Gamma_{2}}=-v(x, y, z, t)
$$

Otherwise, when the rainfall intensity is greater than the surface infiltration capacity of rock and soil mass, the water will be lost along the slope, and the infiltration rate will be the infiltration capacity of rock and soil body itself. In this case, the boundary condition is the head boundary:

$$
\theta_{\Gamma_{1}}=\theta_{1}(x, y, z, t)
$$

(2) The boundary conditions on both sides of the model are related to the groundwater level. The head boundary is set below the groundwater level and zero flow boundary is set above the groundwater level. The bottom is assumed to be impervious boundary.

The rainstorm intensity is $0.018 \mathrm{~m} / \mathrm{h}$, with the rainstorm return period of $30 \mathrm{a}$ and the duration of $6 \mathrm{~h}$. The total simulation time is $24 \mathrm{~h}$. The physical and mechanical parameters of rock and soil mass are shown in Table 1 .
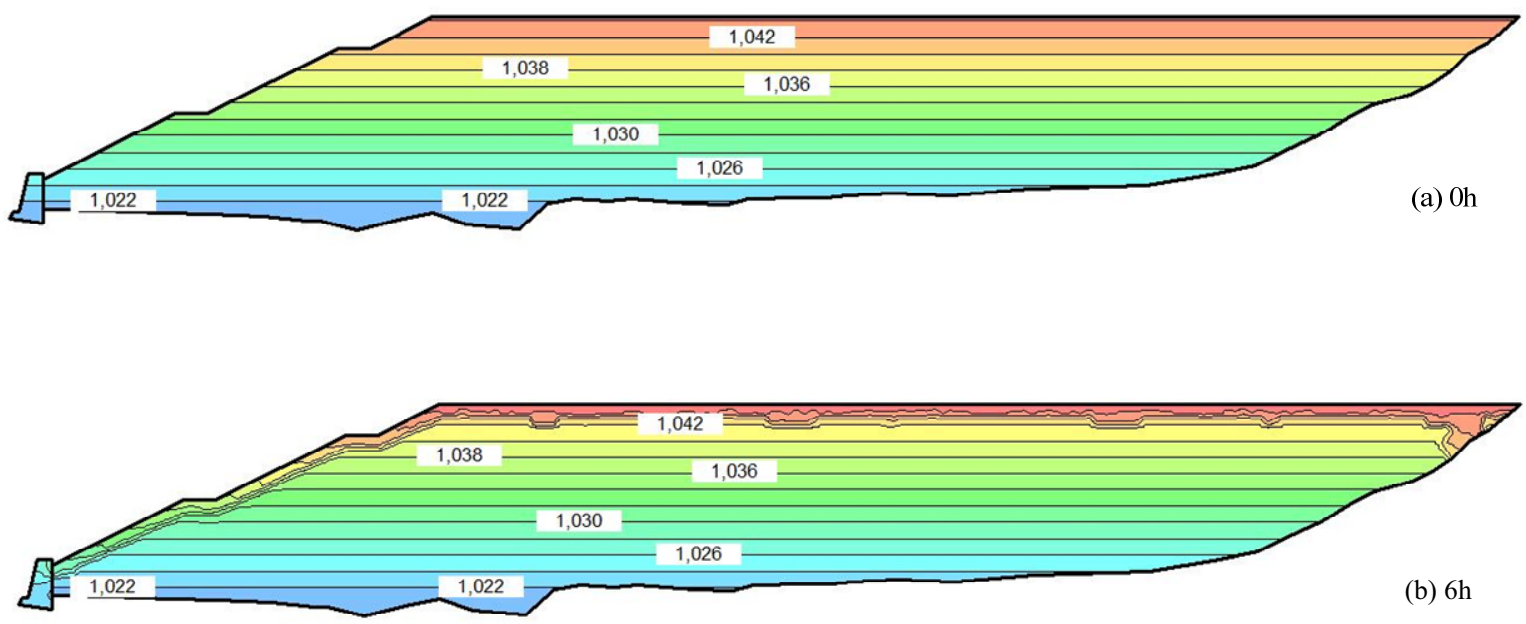


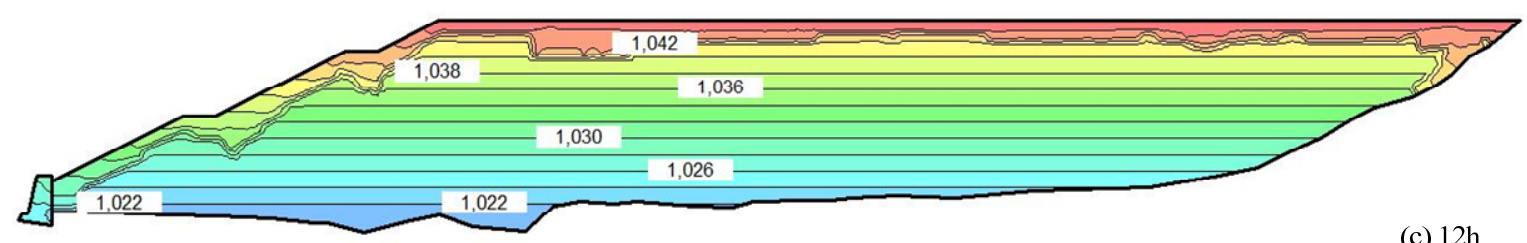

(c) $12 \mathrm{~h}$
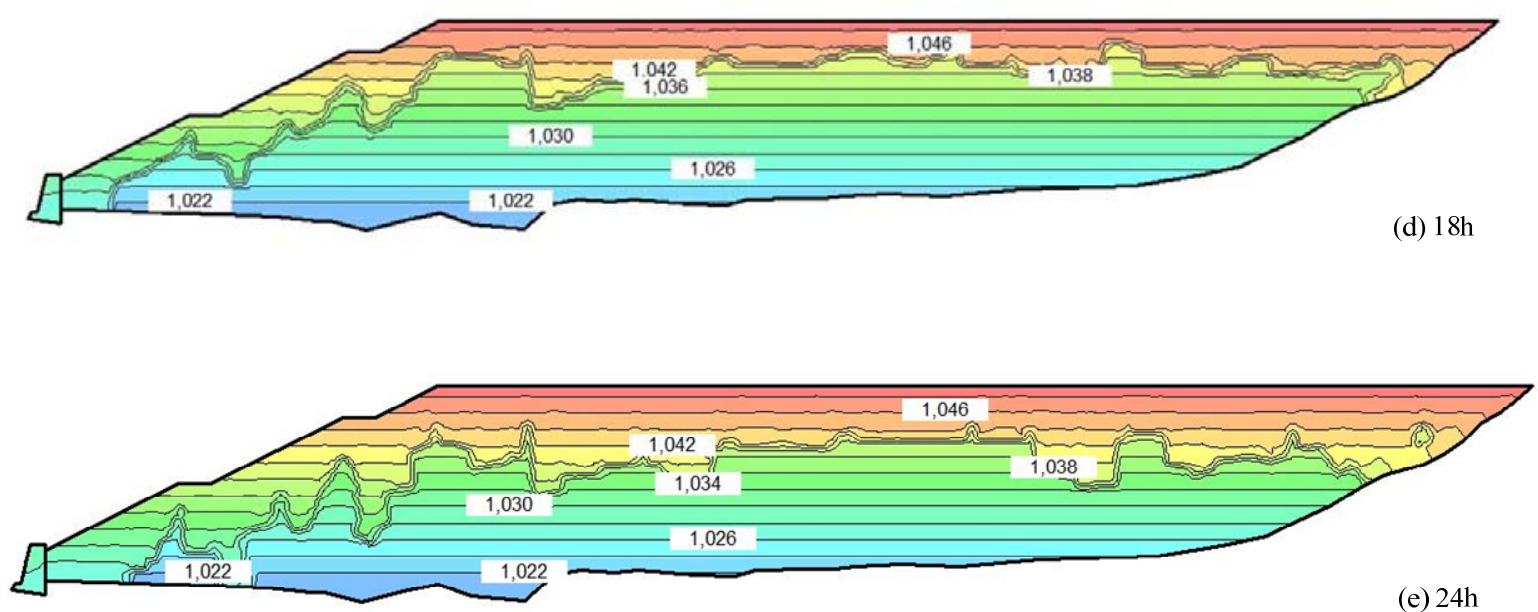

Figure 2. The seepage field

\subsection{Stability analysis}

Morgenstern-Price method allowing for arbitrary shape sliding surface was applied for the slope stability simulation. Figure 3 depicts the slope deformation at different times. As can be seen from the figure, the safety coefficient reduces significantly from the initial 2.793 to the end of the rainfall 2.301. After the rainfall stopped, the stability coefficient decreases slightly due to continuous rainwater seepage. The minimum safety coefficient is 2.292 at $24 \mathrm{~h}$, greater than the allowable value, which demonstrates that the slope is stable.
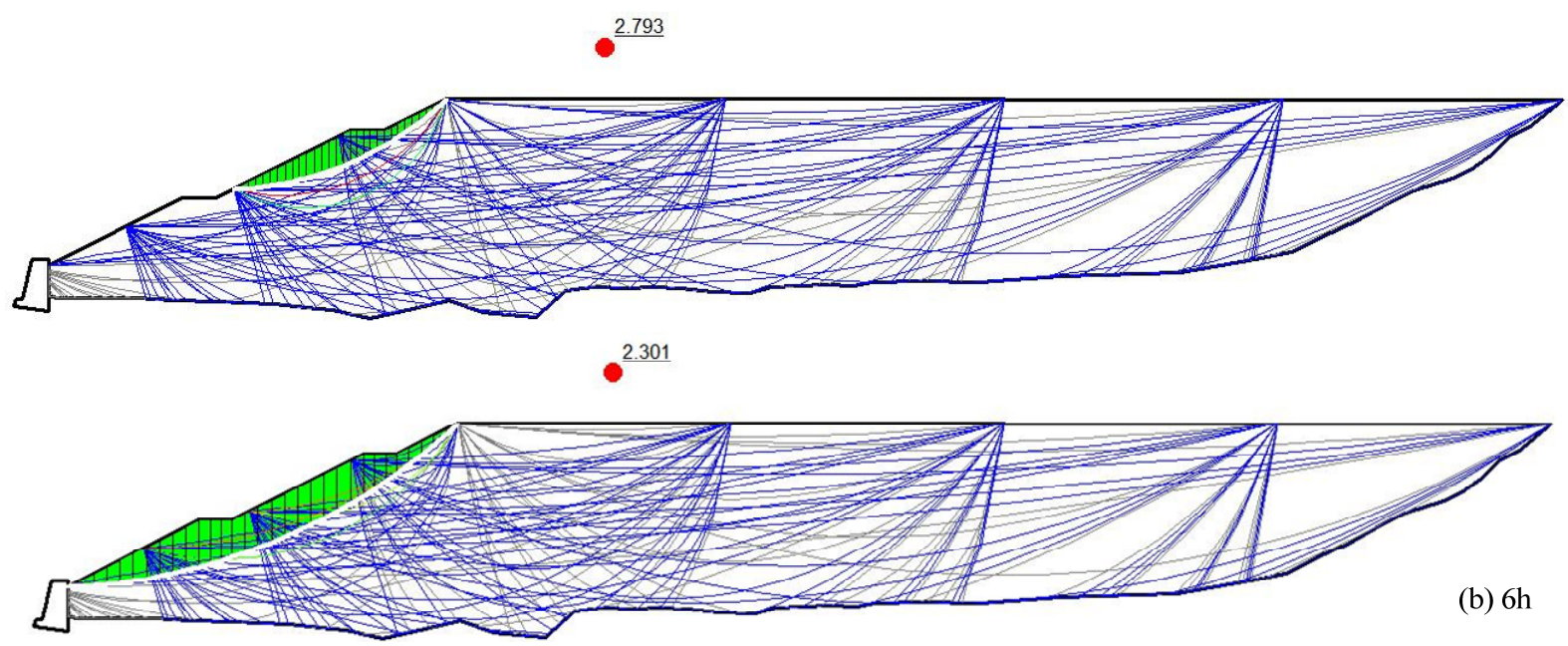

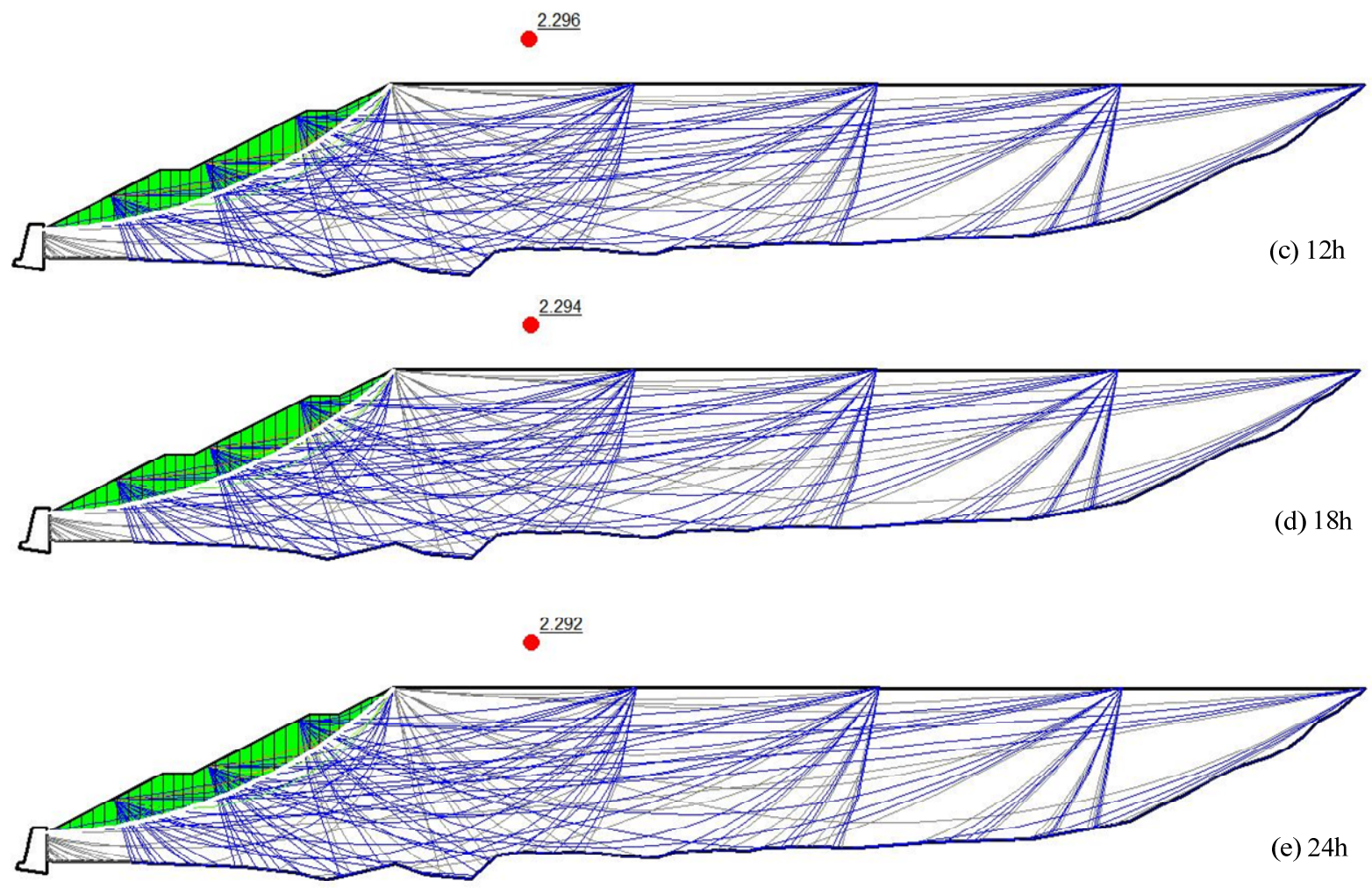

Figure 3. The slope deformation

\section{Conclusion}

(1) The influence of rainfall infiltration on slope seepage field is not limited to the rainfall process. Seepage still exists after the end of rainfall. Therefore, it is far from enough to perform the slope stability analysis only during the rainfall.

(2) The slope stability coefficient decreases significantly during the rainfall and the decreases slightly after the rainfall stopped due to continuous rainwater seepage.

(3) The minimum safety coefficient is 2.292 at $24 \mathrm{~h}$, greater than the allowable value, which demonstrates that the slope is stable.

\section{References}

1. Mao X.S., Song Y.P., Wu Q., Liu L.Q., Xiao Y.J. (2018) Stability analysis of abandoned dreg site slope under condition of seepage flow. Journal of Lanzhou University of Technology, 44(2):139-143.

2. Jiang N., Zhu T.P., Zhao J.W., Zhang L.Q. () Discussion on stability calculation method of spoil ground under rainfall infiltration conditions. Yellow River, 42(10): 96-99, 103.

3. Zhang Y.L., Liu S.C., Zhou P., Yang K.W., Liang S. (2013) Stability analysis of excavation of tunnel opening soil high heading slope based on strength reduction method. Journal of Beijing Jiaotong University, 37(3): 68-72.

4. Liang Z.N., Gong L., Ma X.F., Wu J.L. (2019) Stability analysis of abandoned dreg site for tunnels based on strength reduction method. Subgrade Engineering, 5: 43-46.

5. Zeng L., Fu H.Y., He W., He Z.M., Zhou G.K. (2013) Effects of rainfall infiltration factors on stability of carbonaceous mudstone embankment slope. Journal of Highway and transportation Research and Development, 30(3): 39-44, 58.

6. Yang C., Zuo S.Y. (2019) Study on influence of continuous rainfall on soil slope stability. Subgrade Engineering, 5: 6-11.

7. Qin J.Q., Wang D.Q. (2020) Research on seepage field and stability of highway slope under rainfall conditions. Subgrade Engineering, 5: 120-125. 